\title{
Remote camera-trap methods and analyses reveal impacts of rangeland management on Namibian carnivore communities
}

\author{
Matthew J. Kauffman, M. Sanjayan, Jacob Lowenstein, Adam Nelson, Richard M. Jeo and Kevin R. Crooks
}

\begin{abstract}
Assessing the abundance and distribution of mammalian carnivores is vital for understanding their ecology and providing for their long-term conservation. Because of the difficulty of trapping and handling carnivores many studies have relied on abundance indices that may not accurately reflect real abundance and distribution patterns. We developed statistical analyses that detect spatial correlation in visitation data from combined scent station and camera-trap surveys, and we illustrate how to use such data to make inferences about changes in carnivore assemblages. As a case study we compared the carnivore communities of adjacent communal and freehold rangelands in central Namibia. We used an index of overdispersion to test for repeat visits to individual camera-trap scent stations and a bootstrap simulation to test for correlations in visits to camera neighbourhoods. After distilling our presence-absence data to the most defensible spatial
\end{abstract}

scale, we assessed overall carnivore visitation using logistic regression. Our analyses confirmed the expected pattern of a depauparate fauna on the communal rangelands compared to the freehold rangelands. Additionally, the species that were not detected on communal sites were the larger-bodied carnivores. By modelling these rare visits as a Poisson process we illustrate a method of inferring whether or not such patterns are because of local extinction of species or are simply a result of low sample effort. Our Namibian case study indicates that these field methods and analyses can detect meaningful differences in the carnivore communities brought about by anthropogenic influences.

Keywords Abundance index, camera-trap, carnivores, local extinction, Namibia, rangeland management, spatial correlation, visitation rate.

\section{Introduction}

Increasingly, biologists are recognizing the limitations of protected areas for the long-term maintenance of carnivore populations (Newmark, 1995; Woodroffe \&

Matthew J. Kauffman ${ }^{1}$ Department of Environmental Studies, University of California, Santa Cruz, California, 95064, USA, and Round River Conservation Studies, 284 West 400 North, Suite 105, Salt Lake City, Utah 84103, USA. E-mail mkauffm1@uwyo.edu

M. Sanjayan The Nature Conservancy, 4245 North Fairfax Drive, Arlington, VA 22203, USA.

Richard M. Jeo ${ }^{2}$, Jacob Lowenstein and Adam Nelson ${ }^{3}$ Round River Conservation Studies, 284 West 400 North, Suite 105, Salt Lake City, Utah 84103, USA, and Cheetah Conservation Fund, Otjiwarongo, Namibia.

Kevin R. Crooks Department of Fishery and Wildlife Biology, 115 Wagar, Colorado State University, Fort Collins, CO 80523, USA.

${ }^{1}$ Current address: Wyoming Cooperative Fish and Wildlife Research Unit, U.S. Geological Survey, University of Wyoming, Laramie, WY 82071, USA.

${ }^{2}$ Current address: The Nature Conservancy, 4245 North Fairfax Drive, Arlington, VA 22203, USA.

${ }^{3}$ Current address: Department of Biology, University of Utah, 257 South $1400 \mathrm{E}$ Salt Lake City, UT 84112-0840, USA.

Received 25 January 2005. Revision requested 11 October 2005. Accepted 20 March 2006.
Ginsberg, 1998). Because of the small size of many protected areas successful carnivore conservation must include the management of surrounding unprotected lands (Newmark, 1996; Woodroffe \& Ginsberg, 2000). However, we still have a limited set of tools to assess the conservation value of contrasting land areas for carnivore species. Predators are often difficult to study directly because of their low densities, nocturnal and secretive habits, fierce behaviour, and wariness of humans (Wilson et al., 1996; Sargeant et al., 1998; Stander, 1998). Consequently, the ecology of many carnivore species and their responses to anthropogenic disturbances are often poorly understood (Crooks, 2002).

The objective of this work was to develop a rapid and practical method to combine field surveys and statistical analyses to assess differences in the abundance and distribution of mammalian carnivore assemblages. The approach we outline may be of considerable utility to conservation practitioners in regions of the world where carnivores are threatened or imperiled by as yet unknown anthropogenic changes. Our method uses camera traps to survey several carnivore assemblages in a non-invasive way. Such surveys are often less time-consuming, costly, and invasive than traditional 
research methods such as capture and telemetry (Cutler \& Swann, 1999). Camera-trap surveys are particularly useful for animals such as carnivores that are difficult to trap, handle and observe directly (Bull et al., 1992; Mace et al., 1994; Karanth, 1995; Hernandez et al., 1997; Foresman \& Pearson, 1998; Karanth \& Nichols, 1998), and the resulting photographs are easily identifiable (Cutler \& Swann, 1999). Because of these benefits the use of camera-traps as a tool for conservation and wildlife management is increasingly popular (Carbone et al., 2001).

A critical challenge to interpreting photographic data (and many other surveys using unmarked individuals) is the difficulty of accounting for repeat observations of the same individuals. Most researchers try to avoid this source of error by choosing a spatial scale that minimizes repeat visits, such as inter-station distances greater than the home range of the target species (Zielinski \& Stauffer, 1996). Sargeant et al. (2003) have shown that station indices, which are based on visits to individual scent stations within a transect, are highly correlated to line indices that summarize presence or absence at the level of an entire transect. Here we develop a general approach to determine the spatial scale of sampling that best reduces this source of error in abundance indices, with the aim of improving the efficiency of camera-trap survey techniques across a wide range of species and habitats.

We also develop a probability framework to assess the likelihood of the local extinction of species that were not detected by local surveys as a function of measured visitation rates. Taken together, these analyses extend the utility of camera-trap surveys for the assessment of carnivore diversity, abundance and conservation needs, and anthropogenic threats. As a validation of these methods we use this approach to assess the potential effects of contrasting rangeland management on a diverse carnivore assemblage in central Namibia.

\section{Study area}

In Namibia unprotected rangelands comprise $86 \%$ of the land area and contain up to $90 \%$ of the populations of some large mammal species (Richardson, 1998). These rangelands are used primarily for ranching cattle, smaller livestock, and often game species. Our work focused on the land-use history and carnivore assemblages of adjacent communal and freehold rangelands in the Waterberg region of north-central Namibia (Fig. 1). In this region these two managed lands differ in human population density, grazing pressure, and management objectives (Namibian Directory of Veterinary Service,

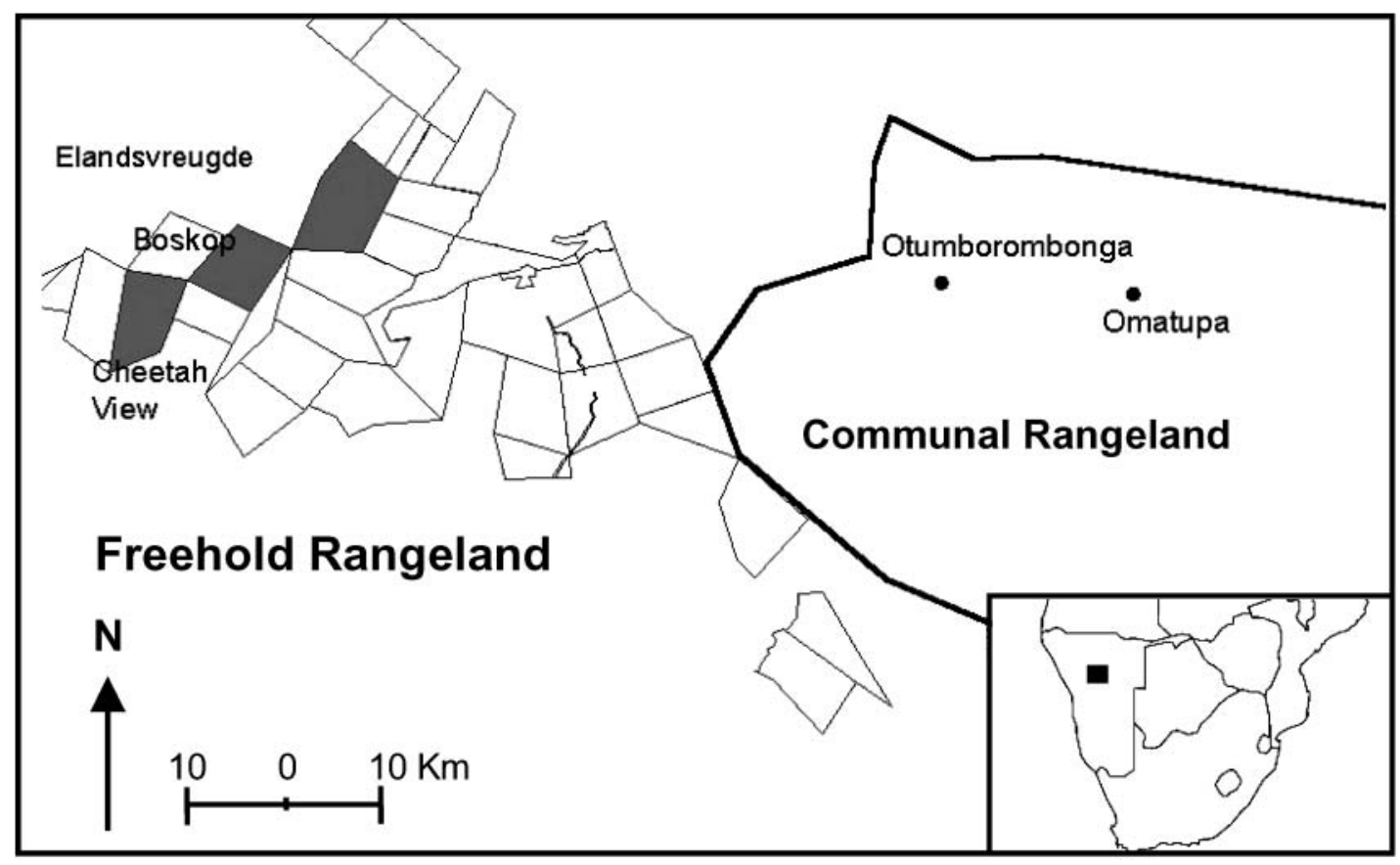

Fig. 1 Study area showing the juxtaposition of freehold and communal rangeland in north central Namibia (see inset for location of main map). Each block represents one freehold ranch; shaded blocks represent the freehold ranches examined in this study. Point locations are shown for the communal rangelands included in carnivore surveys. 
2000, unpubl. data). The communal lands of the Herero people tend to have a much higher human population and are managed for livestock ranching alone. The adjacent freehold rangelands, which are owned privately by single landowners, have a much lower human population and are managed primarily for livestock and game populations. Several native ungulate species such as gemsbok Oryx gazella, eland Taurotragus oryx and red hartebeest Acelaphus buselaphus appear to be common on freehold rangelands but no longer occur on the communal rangelands we studied ( $\mathrm{T}$. Vesee-Vete, pers. comm.). This region supports a diversity of small- to large-bodied carnivores, and we expected that the contrasting management regimes have resulted in different assemblages of carnivore species on communal and freehold lands. Apart from an ongoing carnivore atlas project focused on large carnivores (Hanssen \& Stander, 2006), relatively little is known about the population status of smaller mammalian carnivores in this region.

\section{Methods}

\section{Camera-trap surveys}

We conducted surveys in five study sites, each a freehold or communal rangeland, in central Namibia (Fig. 1). Cheetah View, Boskop and Elandsvreugde are freehold rangelands with a history of ranching activity. Two nearby sites are within communal reserves belonging to the communities of Otumborombonga and Omatupa. All sites lie within a $54 \mathrm{~km}$ radius, experience similar annual rainfall (450 $\mathrm{mm}$ per year on average), and are of similar thornbush savannah habitat.

Within each site we established a linear transect comprising seven or eight Camtrak cameras (Camtrak South, Watkinsville, USA) spaced c. $1 \mathrm{~km}$ apart and mounted along dirt roads or paths rarely used by humans. Cameras were activated by infrared triggering devices and were set to record photographs continuously, with a 3-minute delay after each exposure to avoid consecutive photographs of the same individual. Animals were attracted to the camera stations by applying a cocktail of two liquid carnivore scent lures (Russ Carman's Pro-Choice and Canine Call, Sterling Fur \& Tool, Sterling, USA) in the vicinity of the camera. Scent lure was refreshed every 3 days, with care taken to minimize human scent. Each survey lasted 9 consecutive days, with the first trial beginning on 28 September 2000 and the last trial ending on 10 December 2000. We also recorded the total number of hours each camera had operated, accounting for camera malfunctions such as dead batteries or exhaustion of film. We note that failure to detect a species at a station does not indicate the species never visited the site, because the average latency to first detection for some carnivores may be longer than our 9-day survey duration (Foresman \& Pearson, 1998).

\section{Assessing spatial correlation of visits}

Unless animals are individually marked (Mace et al., 1994; Jacobson et al., 1997) or readily distinguishable based on natural markings (Karanth, 1995; Karanth \& Nichols, 1998), the number of photographs of a species cannot be directly interpreted as the absolute number of individuals in an area. This is due to the inability to determine whether multiple photographs represent multiple visits by the same individual, by different individuals, or a combination thereof. To minimize these sources of error we developed a statistical approach to test for their effect. Our approach assumes that multiple visits from the same individual are spatially aggregated. Such individual behaviour could result in a non-random pattern of camera visits at two spatial scales: (1) multiple visits of a single individual to the same camera will create a spatially clumped (overdispersed) distribution of visits, with some cameras receiving many visits and some cameras receiving no visits; (2) multiple visits of an individual to a camera neighbourhood will result in detectable levels of correlation between adjacent camera stations (Fig. 2). We tested for non-randomness at both spatial scales in order to determine the appropriate level of aggregation of camera data to assess the relative abundance of carnivore species.

To investigate non-randomness due to the occurrence of multiple visits to a camera by the same animal (Fig. 2A) we measured the degree of overdispersion in camera visits within the five transects. We used the standard null assumption of a random distribution of camera visits within a transect, where visits are described by a Poisson distribution with the variance equal to the mean. We calculated an index of dispersion, $I_{D}=(n-1)($ variance $/$ mean $)$, which has a $\chi^{2}$ distribution with $n-1$ degrees of freedom (Southwood \& Henderson, 2000). A statistically significant index of dispersion indicates a clumped distribution of visits within a transect (Fig. 2A). This was used to test for spatially clumped visits of black-backed jackal Canis mesomelas, caracal Felis caracal and African wild cat Felis lybica, the only species for which individual cameras received more than two visits.

To test for non-randomness due to repeat visits to adjacent cameras along a transect (Fig. 2B) we developed a bootstrap simulation that characterized the expected random distribution of visits across adjacent cameras within a transect. In each simulation the observed number of visits per camera was retained, but all spatial structure was destroyed by shuffling the 
A. Multiple visits by a single individual to the same camera station.

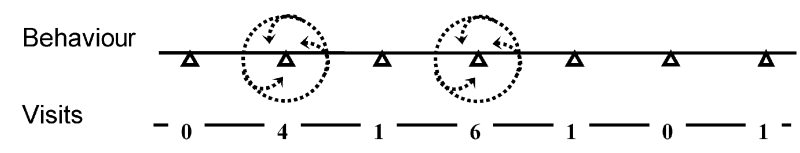

B. Multiple visits by a single individual to a camera neighbourhood.

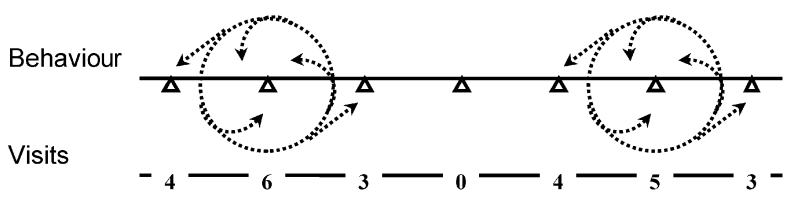

Fig. 2 Illustration of two sources of non-randomness in spatial visitation data. (A) Visits to cameras within a transect are clumped in space due to repeat visits to camera stations by two separate individuals. (B) The number of visits to adjacent cameras is spatially correlated due to multiple visits of the same individual within a camera neighbourhood (i.e. several cameras).

spatial location of each camera within a transect. We then calculated the Spearman rank correlation coefficient between visits for each pair of adjacent camera positions within all five transects. We simulated 1,000 bootstrap correlation coefficients to allow comparison with the observed correlation in animal visits between adjacent camera stations. We conducted this analysis for jackals only, as they were the most common visitor to all camera stations and visits by other species were insufficient to warrant analysis.

\section{Comparing overall carnivore visitation rates}

As our tests for spatial correlation (see Results) suggested that the presence or absence of each species (but not the total number of visits) at each camera over the entire 9-day survey period could be considered an independent observation we collapsed our visitation data to reflect only presence or absence of each species at each camera within a transect. Because we did not have enough data to test for differences in visitation rates for each species individually we conducted an analysis on the presence or absence of all species combined. Thus, the presence or absence of each species at each camera station was modelled as the response variable, with each species by camera combination considered a trial. We used logistic regression analysis (SAS 8.01, Proc Logistic; SAS Institute, Cary, USA) to investigate the following factors influencing visitation rates: (1) the number of hours a camera had operated, (2) the average body mass of each species, and (3) the type of rangeland (freehold or communal management).

\section{Assessing carnivore richness}

Often researchers and conservation planners are interested in the number of species supported by a particular habitat, region, or protected area. In our case study unequal sampling effort ( 3 and 2 transects, respectively, on freehold ranches and communal rangelands), and unequal abundances between management types, constrained our ability to compare species richness between management types directly. When abundance varies between sites, diversity comparisons will favour the more abundant site because of higher species detection rates (Gotelli \& Colwell, 2001). To control for this we used the rarefaction approach implemented with EcoSim (Gotelli \& Entsminger, 2001). We used species accumulation curves to compare richness levels between all pairwise combinations of sites. For each site pair we examined whether or not the observed number of species recorded at the less diverse site fell within the bootstrapped $95 \%$ confidence interval of the more diverse site. We also asked if there was an overall difference between the two rangeland types by conducting a rarefaction analysis that compared the relationship between abundance and richness of all carnivores on freehold vs communal rangelands.

\section{Detecting local extinctions}

We also sought to distinguish whether species missing from some survey sites went undetected because they were locally extinct or because sampling effort was too low. We propose a straightforward method to assess the probability of detecting a species, given that it exists at a particular site. In an analysis of this type we must have an estimate of the underlying (i.e. true) visitation rate for each missing species. In most cases this true visitation rate will be unknown. In comparative studies, however, the global visitation rate can be used as an estimate of the expected visitation rate in sites where species were not detected. Thus, each 'no detection' probability can be modelled as a Poisson process:

$$
\operatorname{Pr}(k=0)=\frac{\mathrm{e}^{-u} u^{k}}{k !}
$$

where $k$ is the number of visits (zero in the case of no detection), and $u$ is the expected number of visits at a site calculated as the product of the visitation rate (visits per hour) and the total number of camera hours.

We were also interested in assessing the probability of not detecting an entire suite of species. If it is assumed species' visits are independent of one another, this can be estimated as the combined probability of each no detection event (for some carnivore assemblages, behavioural responses may cause some species' visits to not be independent of one another; Foresman \& 
Pearson, 1998). Thus, the probability of not detecting $n$ missing species, given that they exist at a site is:

$$
\begin{aligned}
& \text { Probability of no detection }= \\
& \prod_{i=1}^{n} \operatorname{Pr}\left(\text { no detection of } \text { species }_{i}\right)
\end{aligned}
$$

In our case study we used equations 1 and 2 to assess both the likelihood of local species extinction for species that were not detected at specific sites, and the likelihood of not detecting an entire suite of species known to exist in the study area.

\section{Results}

Camera surveys on freehold rangelands recorded many more carnivores visits than did surveys on communal rangelands (Table 1). Ranking all sites by richness showed the freehold sites had consistently more species and that the distribution of species follows approximately a nested pattern, with the rarest species found mostly on the freehold sites. Seven species found on freehold sites were not found on communal sites, whereas only one species (yellow mongoose Cynictis penicillata) found on communal sites was absent from surveys on freehold sites (Table 1). Many of the species missing from the communal rangelands were the largerbodied carnivores such as aardwolf Proteles cristatus, hyena Hyaena brunnea, leopard Panthera pardus, caracal, and honey badger Mellivora capensis.

\section{Spatial clumping of visits}

Analysis of overdispersion indices revealed significant levels of clumping among cameras. The distribution of jackal visits within a transect differed significantly from that expected under a random distribution at all sites (Table 2). Caracal visits were significantly clumped at Cheetah View only, and spatial clumping of African wild cat Felis lybica visits could not be detected at any site (Table 2). The lack of detectable clumping in African wild cats and caracals (at sites other than Cheetah View) is probably a function of low sample sizes (mean number of visits per camera station $\leqslant 0.29$ for all sites except one; Table 2). From this, we concluded that the number of visits to cameras within a transect is typically not random; rather, some cameras are visited frequently (probably by the same individual) while other cameras are visited rarely or not at all.

\section{Spatial correlation of visits between adjacent cameras}

The observed correlation of jackal visits between adjacent camera stations was not statistically different from zero $(r=-0.009, \mathrm{P}=0.958)$; it also fell within the $95 \%$ confidence limits of the bootstrapped distribution of correlation coefficients (Fig. 3). Thus, there is no evidence that a jackal visit at one camera affects the probability of visits to nearby cameras. We therefore pooled the data within each camera to represent presence or absence only of each species. This condensed data set was used for both the logistic regression and rarefaction analysis.

\section{Comparing overall carnivore visitation rates}

Logistic regression analysis indicated that rangeland type was a significant determinant of a species' probability of visiting a camera, with lower overall carnivore visitation rates on communal rangelands

Table 1 Number of visits by carnivore species to rangeland sites in central Namibia. Sites are ranked by richness from left to right. Species

\begin{tabular}{|c|c|c|c|c|c|}
\hline \multirow[b]{2}{*}{ Species } & \multicolumn{3}{|l|}{ Freehold sites } & \multicolumn{2}{|c|}{ Communal sites } \\
\hline & Cheetah View & Boskop & Elandsvreugde & Omatupa & Otumborombonga \\
\hline Black-backed jackal Canis mesomelas & 10 & 12 & 16 & 7 & 6 \\
\hline African wild cat Felis lybica & 6 & 2 & 2 & 0 & 1 \\
\hline Small spotted genet Genetta genetta & 0 & 1 & 2 & 1 & 1 \\
\hline Cape fox Vulpes chama & 0 & 0 & 1 & 1 & 1 \\
\hline Caracal Felis caracal & 9 & 1 & 0 & 0 & 0 \\
\hline Honey badger Mellivora capensis & 4 & 1 & 0 & 0 & 0 \\
\hline Aardwolf Proteles cristatus & 0 & 1 & 1 & 0 & 0 \\
\hline Leopard Panthera pardus & 1 & 1 & 0 & 0 & 0 \\
\hline Striped polecat Ictonyx striatus & 1 & 0 & 0 & 1 & 0 \\
\hline Brown hyena Hyaena brunnea & 3 & 0 & 0 & 0 & 0 \\
\hline Bat-eared fox Otocyon megalotis & 0 & 0 & 3 & 0 & 0 \\
\hline Slender mongoose Galerella sanguinea & 2 & 0 & 0 & 0 & 0 \\
\hline Yellow mongoose Cynictis penicillata & 0 & 0 & 0 & 1 & 0 \\
\hline Total species richness & 8 & 7 & 6 & 5 & 4 \\
\hline Total site visits & 36 & 19 & 25 & 11 & 9 \\
\hline Total camera hours & 1,606 & 1,491 & 1,423 & 1,723 & 1,317 \\
\hline
\end{tabular}
are ordered by their commonness across sites. 
Table 2 Overdispersion tests for visits by jackals, caracals and African wild cats to camera traps on communal and freehold rangelands. Transects where visits are highly clumped have a high index of dispersion, $I_{D}$, indicating that visits do not occur randomly. Sample size (n) is the number of cameras in a transect.

\begin{tabular}{|c|c|c|c|c|c|}
\hline & \multicolumn{3}{|l|}{ Freehold sites } & \multicolumn{2}{|c|}{ Communal sites } \\
\hline & $\begin{array}{l}\text { Cheetah View } \\
(\mathrm{n}=8)\end{array}$ & $\begin{array}{l}\text { Boskop } \\
(\mathrm{n}=7)\end{array}$ & $\begin{array}{l}\text { Elandsvreugde } \\
(\mathrm{n}=8)\end{array}$ & $\begin{array}{l}\text { Omatupa } \\
(\mathrm{n}=8)\end{array}$ & $\begin{array}{l}\text { Otumborombonga } \\
(\mathrm{n}=7)\end{array}$ \\
\hline \multicolumn{6}{|l|}{ Jackal } \\
\hline Variance & 2.50 & 5.90 & 6.57 & 2.13 & 2.14 \\
\hline Mean & 1.25 & 1.71 & 2.00 & 0.88 & 0.86 \\
\hline$I_{D}$ & $14.00^{*}$ & $20.66^{*}$ & $23.00^{*}$ & $17.00^{*}$ & $15.00^{*}$ \\
\hline \multicolumn{6}{|l|}{ Caracal } \\
\hline Variance & 2.70 & 0.14 & & & \\
\hline Mean & 1.13 & 0.14 & & & \\
\hline$I_{D}$ & $16.77^{*}$ & 6.00 & & & \\
\hline \multicolumn{6}{|c|}{ African wild cat } \\
\hline Variance & 1.07 & 0.24 & 0.21 & & 0.14 \\
\hline Mean & 0.75 & 0.29 & 0.25 & & 0.14 \\
\hline$I_{D}$ & 10.00 & 5.00 & 6.00 & & 6.00 \\
\hline
\end{tabular}

*Distribution of visits is significantly overdispersed at $\mathrm{P}<0.05$.

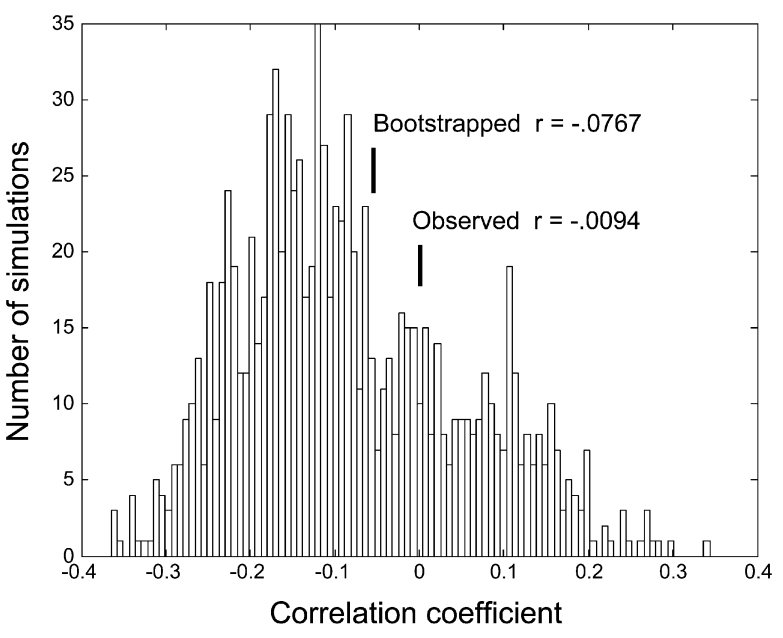

Fig. 3 Distribution of bootstrapped Spearman rank correlation coefficients from 1,000 simulations. The observed correlation of jackal visits between adjacent camera pairs is not statistically different from the distribution of correlation values from the random bootstrapped sample.

(Table 3). Body mass of each species and sampling effort (camera hours) were not significant predictors of visitation rate. The fact that visit probability did not increase for species of smaller body mass or for cameras with longer operating times suggests our 9-day sampling duration was appropriate for most species.

\section{Rarefaction: comparing species richness}

Rarefaction of the source pool of species sampled at each site showed no differences in the relationship between abundance (pooled within cameras) and richness for any site pair. For all pairwise site comparisons the observed richness of the less abundant site fell within the $95 \%$ confidence intervals of the more abundant site. Thus, based on the rarefaction approach we could not distinguish differences in richness due to assemblage composition from differences in richness owing to sample abundance.

We also compared the species accumulation curves for grouped communal and freehold source pools. This analysis tended to support the notion that the communal rangelands are more depauperate than the freehold rangelands (Fig. 4). While this trend is not significant (mean number of communal species always falls with the $95 \%$ confidence interval of the freehold species accumulation curve), it suggests that if both curves were extrapolated out to higher abundances they would have different plateaus, indicative of a difference in species richness.

\section{Detecting local extinctions}

We tested whether or not we would expect to detect the larger-bodied species (aardwolf, hyena, leopard, caracal,

Table 3 Logistic regression analysis of species visits to camera transects. We included camera hours and species body mass as explanatory variables in the full model to account for deviation in number of visits due to small variations in sampling effort and species identity. Whether or not a camera station was located in communal or freehold rangeland was the only significant predictor of visit probability.

\begin{tabular}{llll}
\hline Explanatory variable & Wald $\chi^{2}$ & df & $\mathrm{P}$ \\
\hline Camera hours & 1.8541 & 1 & 0.1733 \\
Species body mass & 1.2474 & 1 & 0.2640 \\
Rangeland type & 8.6602 & 1 & 0.0033 \\
\hline
\end{tabular}




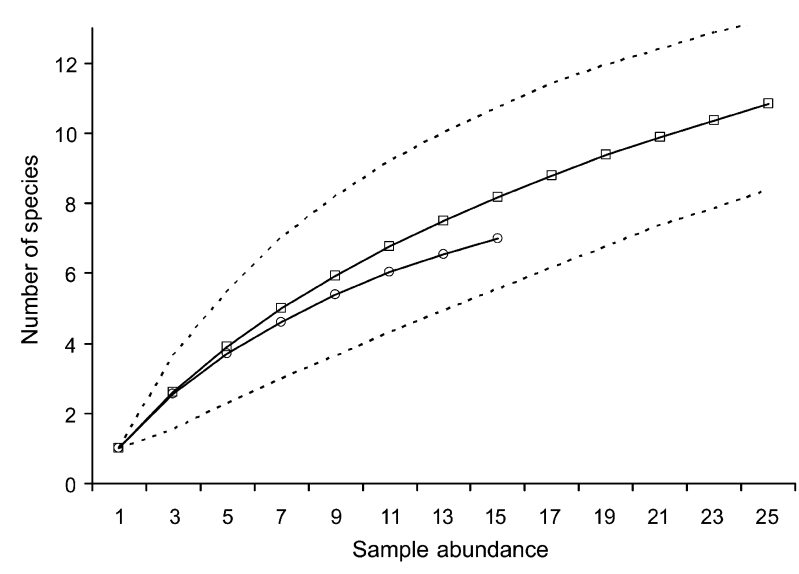

Fig. 4 Rarefaction curves for all species pooled from each rangeland type. Dotted lines are upper and lower $95 \%$ confidence intervals of the freehold carnivore richness at each sample abundance. Open squares denote carnivore data from freehold rangelands and open circles denote communal rangelands.

bat-eared fox Otocyon megalotis and honey badger) missing from the communal rangelands if they actually occurred there. Using the cumulative number of communal camera hours and the freehold visitation rate, we calculated a no-detection probability for each missing species as: caracal $=0.07$, honey badger $=0.13$, hyena $=$ 0.13 , aardwolf $=0.26$, bat-eared fox $=0.26$ and leopard $=0.26$.

We also examined how likely we were to not detect the entire suite of missing species if they all actually occurred on our communal sites. Using equation 2 we concluded that some of these species are locally extinct on communal rangelands because the combined probability of not detecting any of the missing species is small ( $\mathrm{P}<0.0001$ ). However, these species could have escaped our detection on communal lands if they visited the camera traps at rates lower than those on the freehold rangelands. To explore how low these species' visitation rates would have to be to allow them to persist on the communal lands and escape detection by our surveys, we varied the assumed communal visitation rate for each species as a fraction of the observed freehold visitation rate and then recalculated the no detection probability. This showed that all communal species would need to have a visitation rate $<20 \%$ of the freehold rate in order for there to be a $>5 \%$ probability of them all escaping detection (Fig. 5). Thus, if all carnivore species are still extant on the communal rangelands, some exist at low densities.

\section{Discussion}

This case study demonstrates how to utilize noninvasive camera-trap surveys to provide information

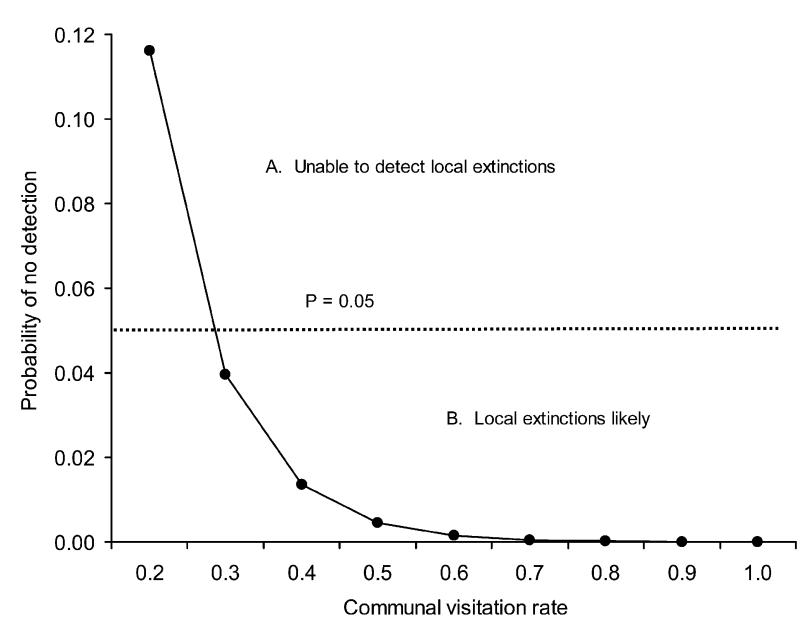

Fig. 5 The ability to detect the local extinction of carnivores on the communal lands depends on the assumptions made about their underlying visitation rates. The probability of not detecting the suite of carnivores missing from our surveys on communal rangelands increases with their assumed visitation rates (shown as a fraction of the observed freehold visitation rates). The dotted line denotes a 'no detection' probability of $\mathrm{P}=0.05$.

on the abundance and distribution of carnivore communities. By combining this rapid wildlife survey method with fairly straightforward statistical methods our approach provides a useful framework for diversity assessments of mammalian carnivore communities. These methods are cost-effective and easy to implement, and based on our case study we suspect they will also be sensitive to changes in community composition.

When individual identification is not possible, camera-trap surveys are limited by the inability to distinguish multiple visits by a single individual from many single visits from multiple individuals (Karanth \& Nichols, 1998). While some studies have shown that indirect surveys for carnivores are proportional to actual abundance (Stander, 1998; Carbone et al., 2001) most studies have only reported visitation data as uncertain indices of relative abundance. By scrutinizing our data for spatial correlations, we have developed a framework to detect the spatial scale that minimizes these sources of error. Using a simple overdispersion test, we detected significant deviations from the expected random distribution of visits (Table 2), which probably results from multiple visits to the same camera by a single individual. However, through simulation we showed a lack of dependence between adjacent camera stations (Fig. 3), as would be expected from an animal that routinely visited a neighbourhood of cameras. We used the spatial correlation of one species (jackal) to determine how to best condense our camera station data. Where higher visitation rates allow, spatial analyses should be conducted on more species to inform 
field sampling and statistical analyses. Thus, this approach provides practitioners with a method of reducing the error associated with repeat visits, without resorting to larger scale data summaries that obscure visitation data taken at smaller spatial scales.

Our Namibian case study indicates this method is capable of detecting changes in carnivore community composition imposed by management practices and anthropogenic influences. The logistic regression analysis indicated reduced visitations of carnivores on communal rangelands (Table 3). Rarefaction analysis comparing the entire pool of carnivore species on the two types of rangelands suggested lower species richness on communal lands (Fig. 4), although limited visitation levels on communal lands makes these results tentative. However, we think it is likely there are real differences in the number of carnivore species in these two land areas, resulting from the local extinction of several of the larger-bodied carnivores on the communal lands. On communal rangelands we failed to detect an entire suite of carnivores (aardwolf, brown hyena, leopard, caracal, bat-eared fox, honey badger and slender mongoose Galerella sanguinea) that we recorded on freehold rangelands. Carnivores not detected on communal rangelands tended to be larger-bodied species. Difference in body size among carnivore species has been proposed as an important determinant of extinction probability (Brown, 1986; Belovsky, 1987) because larger species require larger home ranges, have lower population densities, and are more sensitive to fragmentation and other human disturbances (Lindstedt et al., 1986; Woodroffe \& Ginsburg, 2000; Crooks, 2002). The Poisson analysis to detect local extinctions suggests either that extinctions have occurred on the communal rangelands or these carnivores exist at much reduced densities compared to the freehold rangelands.

Although the sample size of our validation study was small, our results are relevant to the current management of Namibian carnivores. Some likely mechanisms of carnivore decline on the communal rangelands include: (1) increased persecution because of the higher human population density, (2) reductions in the abundance of ungulates (T. Vesee-Vete, pers. comm.) that are prey for larger-bodied predators or scavengers, and (3) negative interactions with the large numbers of domestic dogs (Namibian Directory of Veterinary Service, 2000, unpubl. data). Given such disturbances it may not be surprising that communal rangelands harbour a depauparate carnivore community, although such patterns are not widely documented in the literature.

There may be a link between the history of Namibian land tenure and the viability of its current carnivore fauna. In 1967 freehold landowners gained ownership of game species on their lands, whereas game species on communal reserves remained the property of the State (Griffin, 1998). Collectively, communal residents did not receive the opportunity for ownership of wildlife until the Nature Conservation Amendment Act of 1996. This policy allowed the development of communal Conservancies, which are land management agreements that give greater rights to local communities that manage their lands on the basis of ecological stewardship. Currently, 14 such communal conservancies are registered (MET, 2006), and c. 30 more are under development. Since $41 \%$ of Namibia is communally owned, and the majority of Namibia's growing population lives on communal lands (Lange et al., 1997), improving management of wildlife in these unprotected areas could have a major impact on the country's biodiversity.

\section{Acknowledgements}

We thank the Namibian Ministry of Environment and Tourism for permission to conduct this work (Cheetah Conservation Fund general permit \#35048). Caleb Elder, Jennifer Hunter, Gina Piazza, Jerry Scoville, Ali Scoville and Kitty O'Doherty all made contributions towards preliminary work. Don Murora, Matti Nghikembua, Bruce Brewer and Laurie Marker provided essential logistical support. Bruce Baizel, Roman Biek, Jim Estes, Julie Lockwood, Will Satterthwaite, Priya Shahani, and Phil Stander provided comments on earlier drafts. Dan Doak also reviewed early drafts and provided assistance with statistical analyses. We are also grateful to Petou Malan and the people of Otumborombonga and Omatupa for allowing us to conduct surveys on their land. Most especially, we would like to thank Tjerimo Vesee-Vete for all his support and encouragement with our fieldwork in the communal villages.

\section{References}

Belovsky, G.E. (1987) Extinction models and mammalian persistence. In Viable Populations for Conservation (ed. M.E. Soulé), pp. 35-58. Cambridge University Press, Cambridge, UK.

Brown, J.H. (1986) Two decades of interaction between the MacArthur-Wilson model and the complexities of mammalian distributions. Biological Journal of the Linnean Society, 28, 231-251.

Bull, E.L., Holthausen, R.S. \& Bright, L.R. (1992) Comparison of three techniques to monitor marten. Wildlife Society Bulletin, 20, 406-410.

Carbone, C., Christie, S., Conforti, K., Coulson, T., Franklin, N., Ginsberg, J.R., Griffiths, M., Holden, J., Kawanishi, K., Kinnaird, M., Laidlaw, R., Lynam, A., Macdonald, D.W., Martyr, D., McDougal, C., Nath, L., O'Brien, T., Seidensticker, J., Smith, D.J.L., Sunquist, M., Tilson, R. \& Wan Shahruddin, W.N. (2001) The use of photographic rates to estimate 
densities of tigers and other cryptic mammals. Animal Conservation, 4, 75-79.

Crooks, K.R. (2002) The relative sensitivities of mammalian carnivores to habitat fragmentation. Conservation Biology, 16, 488-502.

Cutler, T.L. \& Swann, D.E. (1999) Using remote photography in wildlife ecology: a review. Wildlife Society Bulletin, 27, $571-581$.

Foresman, K.R. \& Pearson, D.E. (1998) Comparison of proposed survey techniques for detection of forest carnivores. Journal of Wildlife Management, 62, 1217-1226.

Gotelli, N.J. \& Colwell, R.K. (2001) Quantifying biodiversity: procedures and pitfalls in the measurement and comparison of species richness. Ecology Letters, 4, 379-391.

Gotelli, N.J. \& Entsminger, G.L. (2001) EcoSim: Null Models Software for Ecology, version 6. Acquired Intelligence Inc. \& Kesey-Bear, Burlington, USA [http://homepages.together. net/ gentsmin/ecosim.htm, accessed 12 July 2006].

Griffin, M. (1998) The species diversity, distribution and conservation of Namibian mammals. Biodiversity and Conservation, 7, 483-494.

Hanssen, L. \& Stander, P. (2006) Namibia Large Carnivore Atlas. Predator Conservation Trust, Windhoek, Namibia [http:// www.predatorconservation.com/atlas\%20project.htm, accessed 11 November 2006].

Hernandez, F., Rollins, D. \& Cantu, R. (1997) An evaluation of Trailmaster camera systems for identifying ground-nest predators. Wildlife Society Bulletin, 25, 848-853.

Jacobson, H.A., Kroll, J.C., Browning, R.W., Koerth, B.H. \& Conway, M.H. (1997) Infrared-triggered cameras for censusing white-tailed deer. Wildlife Society Bulletin, 25, 547-556.

Karanth, K.U. (1995) Estimating tiger Panthera tigris populations from camera-trap data using capture-recapture models. Biological Conservation, 71, 333-338.

Karanth, K.U. \& Nichols, J.D. (1998) Estimation of tiger densities in India using photographic captures and recaptures. Ecology, 79, 2852-2862.

Lange, G.M., Barnes, J.I. \& Motinga, D.J. (1997) Cattle numbers, biomass, productivity, and land degradation in the commercial farming sector of Namibia, 1915 to 1995. DEA Research Discussion Paper, 17, 1-28.

Lindstedt, S.L., Miller, B.J. \& Buskirk, S.W. (1986) Home range, time and body size in mammals. Ecology, 67, 413-418.

Mace, R.D., Minta, S.C., Manley, T.L. \& Aune, K.E. (1994) Estimating grizzly bear population size using camera sightings. Wildlife Society Bulletin, 22, 74-83.

MET (Ministry of Environment and Tourism) (2006) Community Based Natural Resource Management. Http:/ / www.met.gov. na/programmes/cbnrm/cbnrmHome.htm [accessed 11 November 2006].

Newmark, W.D. (1995) Extinction of mammal populations in western North American national parks. Conservation Biology, 9, 512-526.

Newmark, W.D. (1996) Insularization of Tanzanian parks and the local extinction of large mammals. Conservation Biology, 10, 1549-1556.
Richardson, J.A. (1998) Wildlife utilization and biodiversity conservation in Namibia: conflicting or complementary objectives? Biodiversity and Conservation, 7, 549-559.

Sargeant, G.A., Johnson, D.H. \& Berg, W.E. (1998) Interpreting carnivore scent-station surveys. Journal of Wildlife Management, 62, 1235-1245.

Sargeant, G.A., Johnson, D.H. \& Berg, W.E. (2003) Sampling designs for carnivore scent-station surveys. Journal of Wildife Management, 67, 289-298.

Southwood, T.R.E. \& Henderson, P.A. (2000) Ecological Methods. Blackwell Science, Oxford, UK.

Stander, P.E. (1998) Spoor counts as indices of large carnivore populations: the relationship between spoor frequency, sampling effort and true density. Journal of Applied Ecology, 35, 378-385.

Wilson, D.E., Cole, F.R., Nichols, J.D., Rudran, R. \& Foster, M.S. (1996) Measuring and Monitoring Biological Diversity: Standard Methods for Mammals. Smithsonian Institution Press, Washington, DC, USA.

Woodroffe, R. \& Ginsberg, J.R. (1998) Edge effects and the extinction of populations inside protected areas. Science, 280, 2126-2128.

Woodroffe, R. \& Ginsberg, J.R. (2000) Ranging behaviour and vulnerability to extinction in carnivores. In Behaviour and Conservation (eds L.M. Gosling \& W.J. Sutherland), pp. 125-140. Cambridge University Press, Cambridge, UK.

Zielinski, W.J. \& Stauffer, H.B. (1996) Monitoring Martes populations in California: survey design and power analysis. Ecological Applications, 6, 1254-1267.

\section{Biographical sketches}

Matthew J. Kauffman's work investigates how habitat heterogeneity influences the distribution, population dynamics, and trophic interactions of wildlife species.

M. Sanjayan's work focuses on expanding the role conservation can play in alleviating poverty in rural communities, and how nature can be maintained through the restoration, stewardship, and conservation of ecosystem services.

Jacob Lowenstein and Adam Nelson were undergraduate students in the Round River Conservation Studies Namibia programme when this research was conducted. They are now pursuing graduate studies: Jacob in international wildlife conservation, and Adam in the molecular basis of animal behaviour.

Richard M. Jeo uses the principles of conservation biology to conduct ecoregional assessments and conservation area designs.

Kevin R. Crooks' research investigates the impacts of human disturbances on wildlife, and has often focused on the effects of habitat fragmentation on the behaviour, ecology, and conservation of mammalian carnivores. 